\title{
PERMOHONAN JASA INFRASTRUKTUR TEKNOLOGI INFORMASI DAN OPERASIONAL BERBASIS WEBSITE PADA PT.LAPI LABORATORIES
}

\author{
Ilamsyah $^{1}$, Rosmawati Dwi ${ }^{2}$, Dinny Kurnia Hermawan ${ }^{3}$ \\ ${ }^{1,2,3}$ STMIK Raharja Tangerang' Jl. Jenderal Sudirman No 40 Modern Cikokol Tangerang \\ Email : '1lamsyah@ raharja.info, ${ }^{2}$ rosmawati.dwi@ raharja.info, ${ }^{3}$ dinny.kurnia@ raharja.info
}

\begin{abstract}
The increasing use of technology will increase the need for hardware as one of the support that is very important for the activities of a company. At PT. Laboratories currently have problems in making twoway communication with the user so that required a structured system and realtime presentation of the data that can connect between the user with the division of infrastructure and operations, where the existing system is currently very less effective because it can not present activity data infrastructure division and operations in realtime against requests made by the user, because the user request is only done orally and in the form of internal memo that is not terrecord which can be forgotten anytime, lost or tucked and no output any request report made by the user. As for the data collection in this research is done by interview method, observation and literature study. The result of this research is in the wake of application system of information technology services especially the infrastructure and operational part which clear and structured from the beginning of application is made, progress until application is complete. Reports of progress workmanship and application can be printed.
\end{abstract}

Keywords : Application for services, Real time, website

\begin{abstract}
Abstrak
Semakin meningkatnya pemanfaatan teknologi maka akan semakin meningkat juga kebututuan akan perangkat keras sebagai salah satu penunjang yang sangat penting untuk aktifitas suatu perusahaan. Pada PT. Laboratories saat ini terdapat masalah dalam melakukan komunikasi dua arah dengan user sehingga diperlukan suatu sitem yang terstruktur dan realtime penyajian datanya yang dapat menghubungkan antara user dengan divisi infrastruktur dan operasional, Dimana sistem yang ada saat ini sangat kurang efektif karena tidak dapat menyajikan data aktifitas divisi infrastruktur dan operasional secara realtime terhadap permintaan yang dilakukan oleh user, karena permintaan user hanya dilakukan secara lisan maupun tulisan berupa internal memo yang tidak terrecord yang kapan saja bisa terlupakan, hilang atau terselip dan tidak ada output laporan permintaan apa saja yang dilakukan oleh user. Adapun dalam pengumpulan data pada penelitian ini di lakukan dengan metode wawancara, observasi dan studi pustaka. Hasil dari penelitian ini adalah di bangunnya sistem permohonan jasa teknologi informasi khususnya bagian infrastruktur dan operasional yang jelas dan terstruktur dari awal permohonan dibuat, progress sampai permohonan selesai.

Laporan-laporan berupa progress pengerjaan dan permohonan dapat di cetak.
\end{abstract}

Kata Kunci : Permohonan jasa, Real time, website 


\section{PENDAHULUAN}

PT. LAPI Laboratories pada awalnya merupakan sebuah klinik dan laboratorium asma dan alergi pertama di Indonesia yang didirikan oleh Dr.Indrayana pada tahun 1974. Nama LAPI sendiri merupakan singkatan dari Laboratorium Asma dan Alergi Pertama di Indonesia. Seiring dengan berjalannya waktu, PT. LAPI Laboratories berkembang menjadi sebuah industri farmasi yang maju, dan pada tahun 1994 PT. LAPI laboratories membangun pabrik di Kawasan Industri Modern Cikande, Serang, Kav 18.

Semakin meningkatnya pemanfaatan teknologi maka akan semakin meningkat juga kebutuhuan akan perangkat keras untuk menunjang setiap aktifitas suatu perusahaan termasuk PT. Lapi Laboratories, keberadaan akan perangkat keras merupakan suatu kebutuhan hampir disemua aktifitas yang dilakukan user pada PT. Lapi Laboratories. Semakin tinggi aktifitas user maka akan timbul juga berbagai permasalahan dan kendala seputar pemanfaatan perangkat keras sebagai sarana penunjang aktifitas kerja, untuk mengatasi hal tersebut dibentuklah suatu divisi yang khusus menangani permasalahan yang dihadapi oleh user yaitu divisi infrastruktur dan operasional oleh PT. Lapi Laboratories. Divisi infrastruktur dan operasional pada PT. Lapi Laboratories bertugas menyelesaikan permasalahan-permasalahan yang dilaporkan oleh user seputar kerusakan, perbaikan perangkat keras maupun permasalahan seputar dunia teknologi informasi. Untuk mempermudah aktifitas divisi infrastruktur dan operasional bagian TI dalam melakukan komunikasi dengan user diperlukan suatu sitem yang terstruktur dan realtime penyajian datanya yang dapat menghubungkan antara user dengan divisi infrastruktur dan operasional, karena sistem yang ada saat ini sangat kurang efektif karena tidak dapat menyajikan data aktifitas divisi infrastruktur dan operasional secara realtime terhadap permintaan yang dilakukan oleh user, sistem yang ada saat ini sangat sering sekali terjadi human error karena permintaan user hanya dilakukan secara lisan maupun tulisan berupa internal memo yang tidak terrecord yang kapan saja bisa terlupakan, hilang atau terselip dan tidak ada output laporan permintaan apa saja yang dilakukan oleh user. Dari latar belakang yang sudah dijelaskan sebelumnya maka permasalahan yang dibahas pada penelitian ini yaitu bagaimana permohonan jasa infrastruktur teknologi informasi dan operasional pada pt.lapi laboratories saat ini dan sistem seperti apakah yang harus di bangun untuk PT. Lapi Laboratories khususnya yang dibutuhkan oleh user dan divisi infrastruktur dan operasional PT. Lapi Laboratories. . Prosedur dalam proses penanganan jasa infrastruktur \& operasional adalah salah satu tugas dari personil bagian IT (Informasi Teknologi), dimana di dalam menjalankan sistem penanganan jasa infrastruktur \& operasional di PT. Lapi Laboratories mempunyai beberapa kegiatan operasional yang saling mendukung dan saling terkait serta berhubungan dengan beberapa bagian lain yang berperan sebagai kesatuan luar (external entity).

penelitian ini dilakukan terbatas pada proses permohonan jasa infrastruktur teknologi informasi dan operasional yang dilakukan oleh karyawan PT. Lapi Laboratories terhadap bagian Informasi teknologi. Adapun batasan masalah penelitian ini yaitu pada pemberian informasi seputar, input permohonan, input penanganan dan report laporan. Dengan dilakukannya penelitian ini diharapkan dapat mempermudah penyampaian dan pengolahan informasi permintaan permohonan jasa teknologi Informasi antara user/karyawan PT. Lapi Laboratories pada bagian teknologi Informasi yang dilakukan melalui pembbuatan sistem informasi permohonan jasa teknologi Informasi yang memudahkan bagian teknologi Informasi dan seluruh karywan PT. Lapi yang membutuhkan bantuan/jasa teknologi informasi sehingga memudahkan pemberian laporan aktivitas permohonan jasa teknologi informasi kepada manager bagian teknologi informasi. 


\section{METODE PENELITIAN}

Pada penelitian ini sumber data yang digunakan adalah data primer yang di dapat dari Tanya jawab langsung dengan responden khususnya bagian IT dan Operasional pada PT. Laboratories. Adapun secara lebih lengkap penelitian ini dilakukan dengan cara :

a. Metode observasi

Melalui metode ini penulis melakukan observasi langsung di PT. Lapi Laboratories, observasi dilakukan guna melihat langsung proses kerja yang berjalan.

b. Metode wawancara

Penulis melakukan wawancara langsung kepada Supervisor yang bersangkutan yang bekerja pada PT. Lapi Laboratories yaitu Bapak Windu Tri Utomo S.Kom yang saat ini menjabat sebagai Supervisor Informasi Teknologi, dengan melakukan tanya jawab seputar pekerjaan yang dilakukan, guna menghasilkan suatu informasi yang relevan dimana objek penelitian dilakukan.

c. Metode studi pustaka

dari metode pustaka ini, penulis mencari referensi dari beberapa jurnal baik nasional maupun internasional yang masih berhubungan dengan judul yang di ambil, serta melakukan searching pada internet dan buku-buku yang sejenis.

Dari penelitian yang dilakukan diatas didapatkan informasi bahwa bagian yang terkait dalam proses penanganan jasa infrastruktur \& operasional adalah salah satu tugas dari personil bagian IT (Informasi Teknologi), dimana di dalam menjalankan sistem penanganan jasa infrastruktur \& operasional di PT. Lapi Laboratories mempunyai beberapa kegiatan operasional yang saling mendukung dan saling terkait serta berhubungan dengan beberapa bagian lain yang berperan sebagai kesatuan luar (external entity). Melihat permasalahan yang ada pada PT. Lapi Laboratories khususnya pada bagian IT (Informasi Teknologi), maka penelitian ini membahas tentang bagaimana pembuatan permohonan jasa teknologi informasi khususnya pada bagian infrastruktur \& operasional untuk menampilkanReport progress status permohonan serta report pekerjaan yang dilakukan oleh teknisi dan supervisor.

Untuk memahami permasalahan pada topik yang akan dibahas, terlebih dahulu diperlukan pengetahuan tentang segala sesuatu yang berhubungan dengan topik bahasan, diantaranya :

\section{Infrastruktur Teknologi}

pengertian infrastruktur adalah fasilitas mendasar yang dibutuhkan untuk menjalankan sebuah sistem termasuk pelayanan dan segala sesuatu yang dibutuhkan dalam proses bisnis. Atau dalam kaitannya dengan IT, infrastruktur dibutuhkan untuk menciptakan lingkungan lingkungan yang terkomputerisasi yang menjadi kunci bagi efektifitas dan efisensi. 


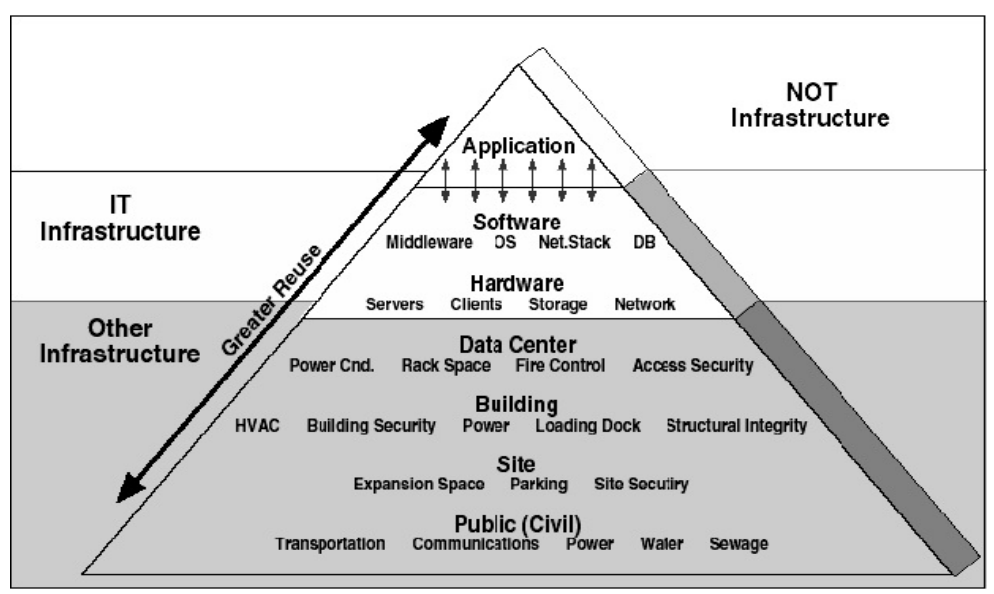

Gambar 1 Infrastruktur Teknologi informasi

Melalui Gambar diatas dijelaskan bahwa infrastruktur teknologi informasi sebagai struktur yang memberikan layanan dan dukungan terhadap lapisan di atasnya yaitu pengembangan aplikasi. Infrastruktur teknologi informasi merupakan prasarana penunjang utama sumber daya teknologi dalam terselenggaranya proses penyebaran informasi. Pengertian infrastruktur teknologi informasi yang dikemukakan oleh james parsee $(2014: 1)^{[1]}$, Infrastruktur teknologi informasi merupakan pondasi dasar dari kapabilitas teknologi informasi. Kapabilitas teknologi informasi ini meliputi internal technical (equipment, software dan cabling) maupun human expertise yang dibutuhkan untuk memberikan pelayanan yang dapat dipercaya. Menurutnya Infrastruktur teknologi informasi memberikan pondasi dasar bagi kapabilitas teknologi informasi yang digunakan untuk membangun aplikasi bisnis dan biasanya dikelola oleh kelompok sistem informasi.

\section{Infrastruktur Teknologi Informasi yang Adaptif}

Infrastruktur teknologi informasi yang adaptif adalah infrastruktur yang dapat menyesuaikan diri dengan keadaan dan dibuat fleksibel untuk dapat mengakomodasi perubahan-perubahan yang terjadi secara efisien. Alasan mengapa dibutuhkan infrastruktur teknologi yang adaptif cukup sederhana, hal ini disebabkan karena dunia bisnis baik termasuk lembaga profit maupun non-profit seperti perpustakaan begitu cepat berubah, sedangkan perubahan teknologi informasi tidak bisa dilakukan secepat itu. Sehingga perlu disiapkan infrastruktur yang bisa mengantisipasi banyak perubahan untuk jangka waktu yang cukup panjang.

Menurut Robertson dan Sribar (2015) ${ }^{[2]}$, manifestasi dari infrastruktur teknologi informasi yang adaptif adalah:

1. Efficiency, dengan tersedianya komponen-komponen yang dapat dimanfaatkan bersama oleh berbagai sistem aplikasi baik lama maupun baru.

2. Efectiveness, dengan komponen-komponen yang mudah dipadukan (interoperable) dan di integrasikan.

3. Agility, dengan komponen-komponen yang mudah dirombak, di-upgrade, atau diganti.

Permasalahan yang sering timbul adalah penerapan infrastruktur teknologi informasi yang tidak terencana dengan baik serta tidak terkoordinasinya perencanaan infrastruktur dengan strategi dan pengembangan sistem informasi. Seringkali pengembangan infrastruktur menyesuaikan dengan kebutuhan- kebutuhan aplikasi-aplikasi baru tanpa adanya standarisasi. 


\section{Penelitian yang terkait}

Beberapa penelitian yang terkait dan berhubungan dengan topic penelitian yang dibahas antara lain :

1. Penelitian yang telah dijalankan oleh Bahrul Ulum (2014) ${ }^{[3]}$ berjudul "Sistem permintaan jasa perbaikan komputer PT. Indo Tirta Abadi ", pada tahun 2014. Rancangan program yang diusulkan pada penelitian ini menggunakan program php. Pembahasannya hanya dibatasi pada permohonan jasa perbaikan komputer saja. Oleh karena itu penelitian ingin lebih dikembangkan lagi sehingga tidak terbatas lagi hanya pada permohonan jasa perbaikan komputer.

2. Penelitian yang dijalankan oleh Dini Amelia Rahmah (2013) ${ }^{[4]}$ berjudul " Sistem Pemohonan bantuan Helpdesk Berbasis Website Pada Dinas Koperasi Daerah Jawa Tengah ". Pada tahun 2013, Metode yang diusulkan pada penelitian ini menggunakan program PHP. Pembahasannya hanya dibatasi pada Pemohonan bantuan Helpdesk

3. Penelitian yang dijalankan oleh Nurhadianto (2013) berjudul "Sistem Permohonan jasa Infrastruktur pada PT.Saedong Cikande-Serang ”. Pada tahun 2013 ${ }^{[5]}$, Metode yang diusulkan pada penelitian ini menggunakan program aplikasi PHP. Pembahasannya hanya dibatasi pada Permohonan jasa Infrastruktur saja. Oleh karena itu penelitian ini akan lebih dikembangkan lagi agar lebih optimal.

4. Penelitian yang dilakukan oleh Ana Zaiat, Rosaldo J. F. Rossetti, Ricardo J.S. Coelho. Pada tahun 2014 ${ }^{[6]}$ dengan judul "Towards An Integrated Multimodal Transportation services ticketing" menyatakan bahwa ticketing adalah alat penting untuk pemantauan dan pengelolaan sistem transportasi, memberikan informasi yang diperlukan untuk perencanaan strategis dan darurat kepada pihak berwenang dan pengambil keputusan lainnya pada sector tersebut.

5. Penelitian ini dilakukan oleh Maëlick Claes, Tom Mens, Philippe Grosjean pada tahun 2014 ${ }^{[7]}$ dengan judul "Maintainer: "A Web-Based Ticketing For Maintainers of CRAN Packages" menyatakan bahwa ticketing berbasis web yang memungkinkan pengembang paket CRAN memahami dan menangani implikasi dan masalah yang timbul dari pembaruan paket. Dasbor melengkapi alat analisis yang ada dengan memberikan dukungan tambahan seperti visualisasi dependensi paket dan dependensi terbalik, konflik paket, kloning fungsi paket silang, dan sebagainya.

\section{HASIL DAN PEMBAHASAN}

dari penelitian yang telah dilakukan didapatkan urutan prosedur system permohonan jasa yang berjalan saat ini adalah :

User melakukan permohonan jasa teknologi informasi menggunakan internal memo untuk kemudian diterima oleh supervisor dan mencatat permohonan untuk disetujui/ditolak. Selanjutnya dilakukan pendelegasian kepada staff IT untuk memfollow up permohonan dengan mengintruksikan kepada staff teknologi informasi untuk melakukan perbaikan terhadap permohonan dari user. Setelah dilakukan follow up oleh staff IT maka staff IT memberikan catatan pekerjaan kepada supervisor dan supervisor memastikan penyelesaian permohonan yang di kerjakan oleh staff dan melakukan review permohonan secara keseluruhan. Jika digambarkan urutan prosedur diatas dalam bentuk diagram didapatkan diagram use case sebagai berikut : 


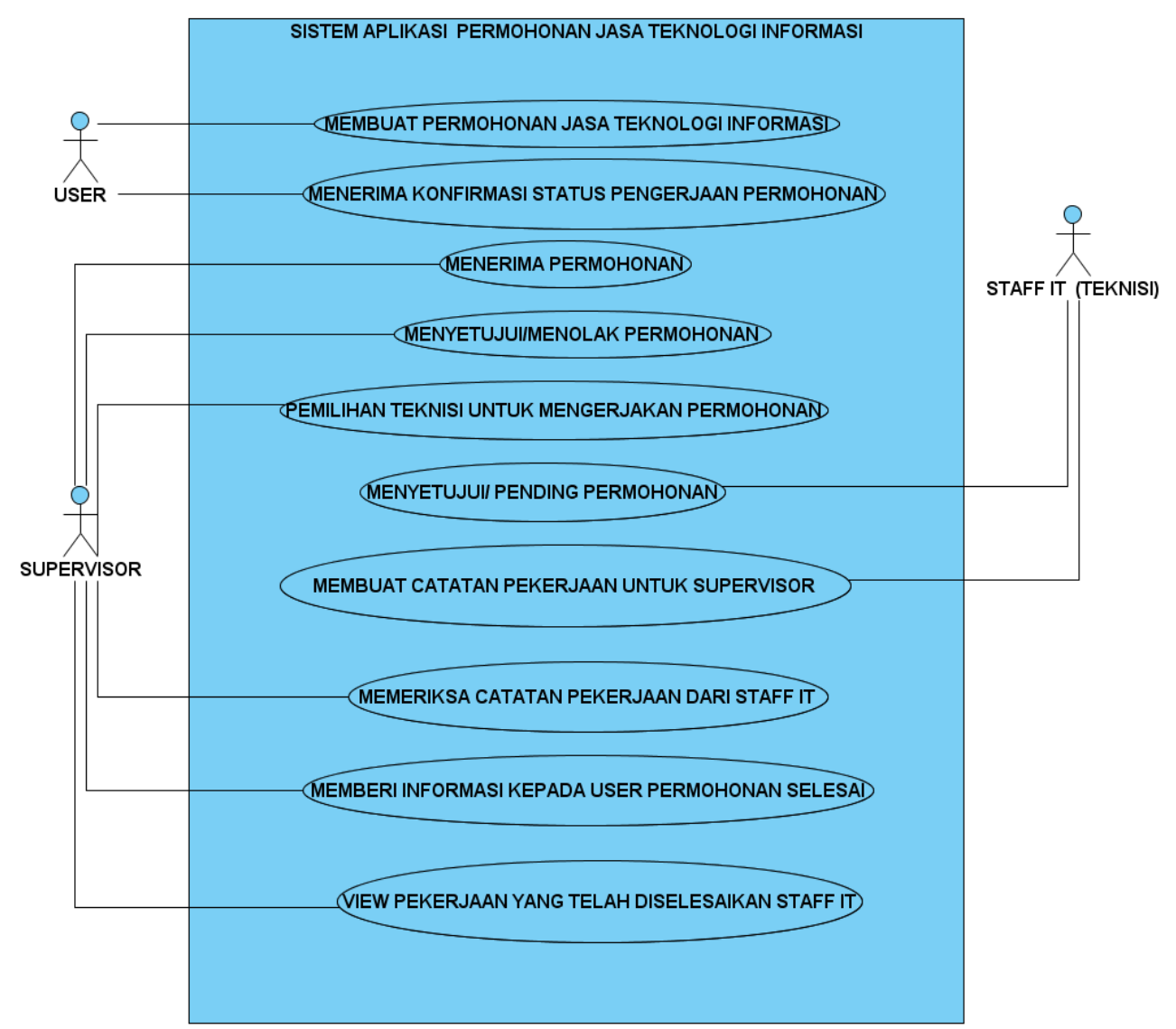

Gambar 2. Diagram use case system berjalan

Berdasarkan diagram diatas dapat dilihat bahwa proses permohonan jasa teknologi informasi khususnya pada bagian infrastruktur dan operasional yang dilakukan saat ini sangat tidak efektif dan tidak terkomputerisasi. Oleh karena itu, dibutuhkan suatu software (perangkat lunak) sistem informasi yang dapat menunjang bagian infrastruktur dan operasional dalam melakukan aktifitas dan pekerjaanya.

Oleh karena itu, dibutuhkan penyempurnaan terhadap sistem yang sedang berjalan saat ini sehingga dapat meningkatkan kualitas kerja bagian infrastruktur dan operasional pada PT. Lapi Laboratories. Maka diusulkanlah sebuah sistem berbasis website yang bertujuan untuk mencapai tujuan tersebut.

Berdasarkan hasil wawancara dengan pihak terkait mengenai kebutuhan sistem baru yang ingin dibuat perlu dibuat sebuah rancangan prosedur yang dapat dilihat pada diagram dibawah ini. 


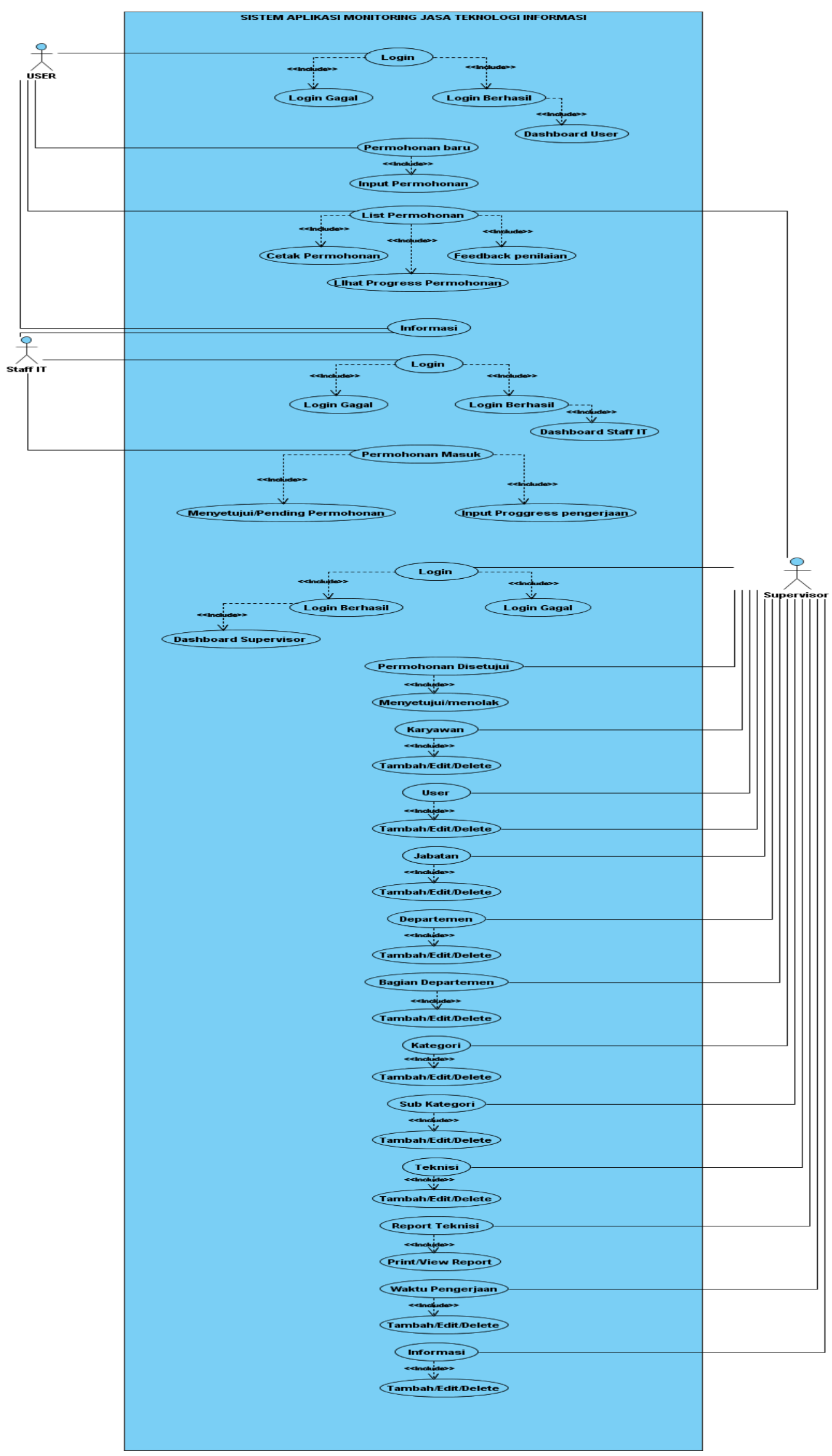

Gambar 3. Use case diagram sistem yang diusulkan 
Dari diagram diatas dapat dilihat bahwa pemohon atau user dapat melakukan request untuk permohonan jasa infrastruktur IT atau permohonan perbaikan yang selanjutnya user akan melakukan input keterangan tentang kebutuhan user untuk selanjutnya supervisor akan menetukan apakah permohonan tersebut di setujui atau di tolak. Permohonan yang disetujui akan langsung di teruskan kepada bagian IT untuk ditindaklanjuti. Bagian IT akan dapat melihat permohonan yang disetuji melalui dashboard system. Dengan sistem berbasis website ini setiap permintaan yang diajukan oleh user akan terekam dengan baik sehingga apabila suatu saat diperlukan penelusuran data permintaan oleh user akan lebih mudah untuk dilakukan.

Tahap selanjutnya yang dilakukan adalah perancangan database yang diperlukan. Tools yang digunakan diantaranya adalah class diagram yang disajikan pada gambar di bawah ini :

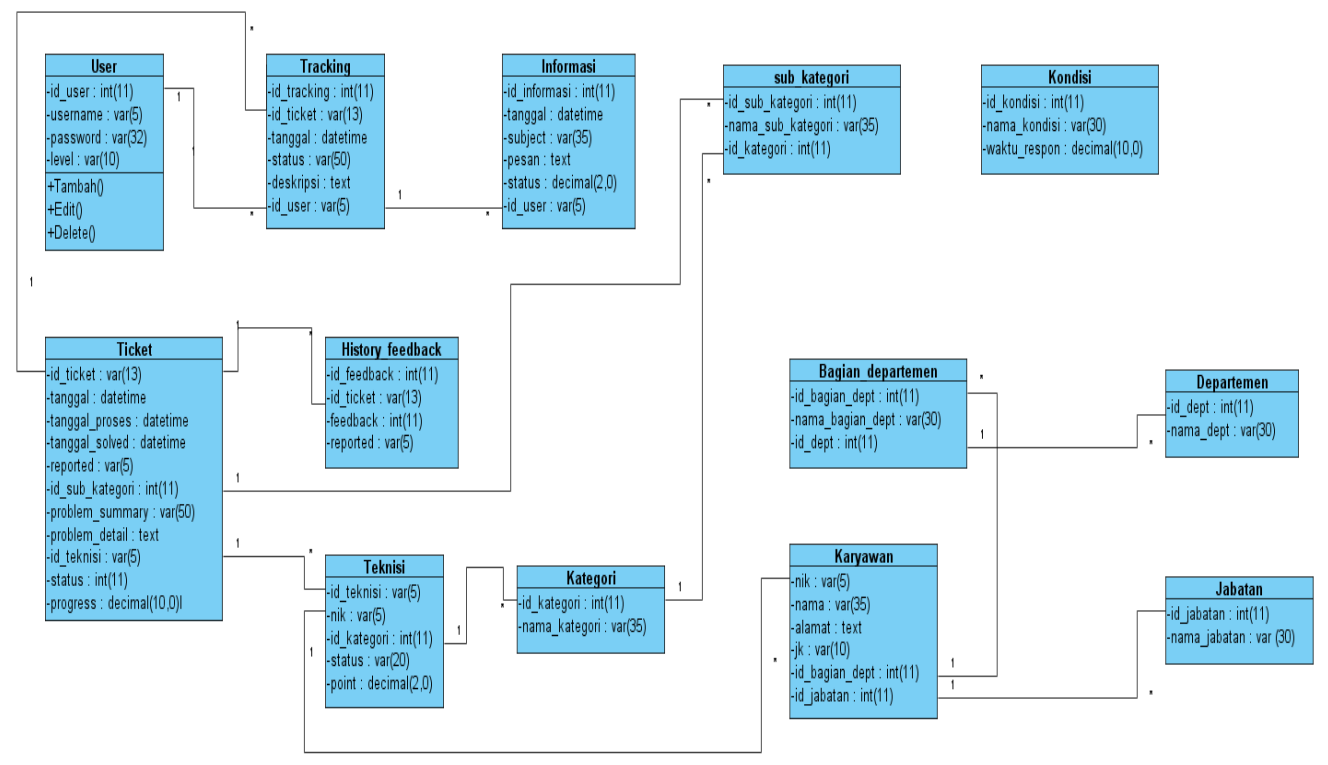

Gambar 4. Class diagram sistem yang diusulkan

Berdasarkan Gambar Class Diagram yang diusulkan terdapat 13 class, himpunan dari objekobjek yang berbagi atribut serta operasi yang sama. Dari class diagram ini yang selanjutnya akan dibuat tabel sebagai acuan untuk melakukan perancangan antar muka.

\section{Rancangan Tampilan Antar Muka yang Diusulkan}






\section{Gambar 5. Rancangan Tampilan Halaman Home User}

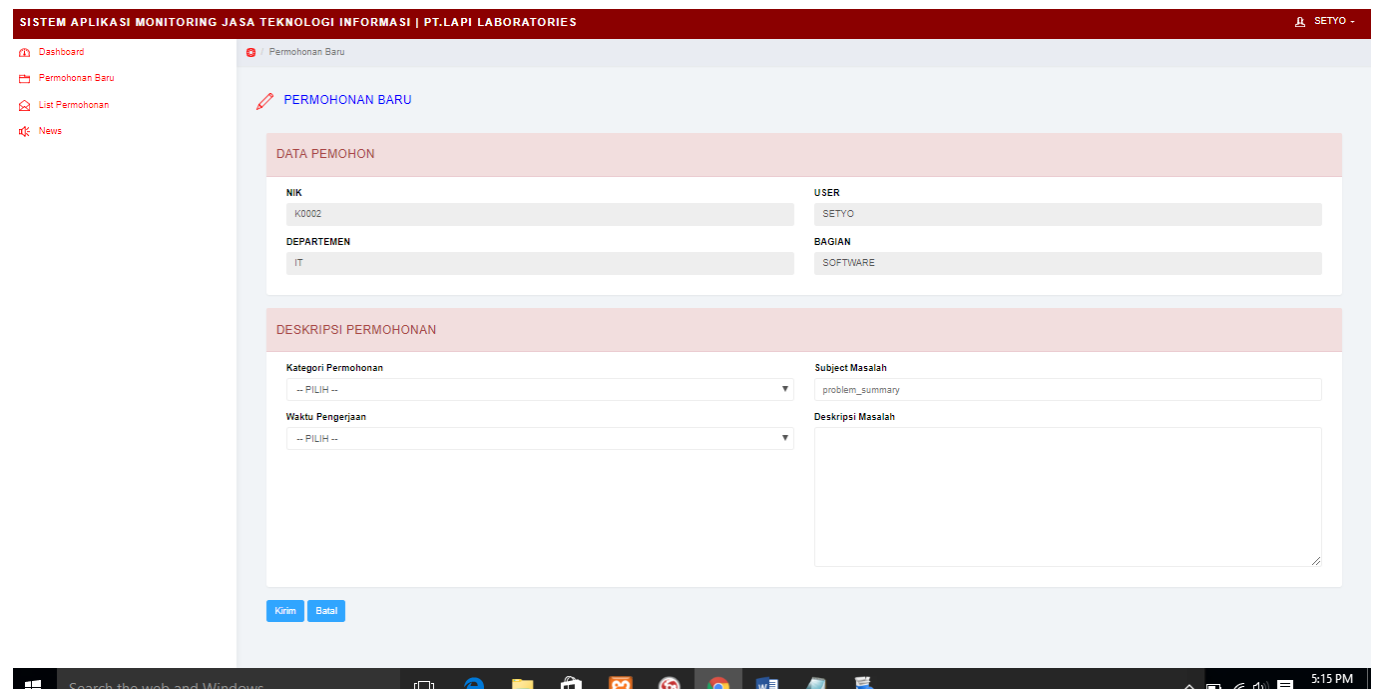

Gambar 6. Rancangan Tampilan Dashboard Permohonan

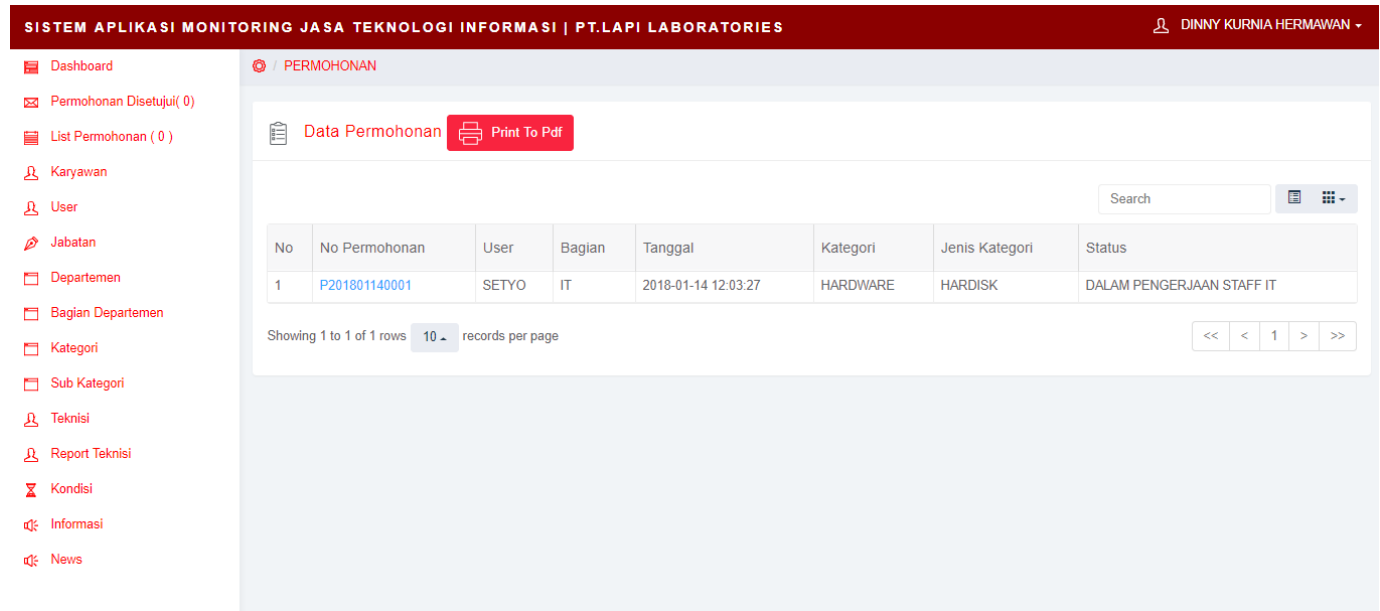

Gambar 7. Rancangan Tampilan Halaman List Permohonan

\section{KESIMPULAN}

Berdasarkan pembahasan dan hasil penelitian yang telah diuraikan pada bab sebelumnya, maka penulis menarik beberapa kesimpulan sebagai berikut:

1. Sistem permohanan jasa teknologi informasi yang saat ini berjalan masih kurang efektif karena semua data permohonan tidak tercatat dengan baik karena masih sangat manual dan status permohonan yang dilakukan oleh user tidak dapat di telusuri alur progressnya .

2. Penelitian ini dapat membangun sistem permohonan jasa teknologi informasi khususnya bagian infrastruktur dan operasional yang jelas dan terstruktur dari awal permohonan dibuat, progress sampai permohonan selesai.

3. Laporan-laporan berupa progress pengerjaan dan permohonan dapat di cetak/printout. 


\section{SARAN}

Saran atau masukan yang dapat penulis berikan untuk menunjang atau pengembangan sistem selanjutnya adalah sebagai berikut:

1. Sebaiknya untuk mengoptimalkan penggunakan aplikasi permohonan jasa teknologi informasi ini ditempatkan pada sebuah server yang memiliki spesifikasi maximal karena dalam penggunaanya akan ada banyak user yang mengakses aplikasi ini.

2. Pastikan selalu melakukan backup aplikasi permohonan jasa teknologi informasi baik itu source code maupun databasenya..

3. Pengembangan terhadap sistem ini agar dapat dibuat menjadi lebih baik dari segi keamanan datanya ataupun dari segi tampilannya dan efektifitasnya.

\section{DAFTAR PUSTAKA}

[1]. James Persse. 2014, Project Management Success with CMMI (seven cmmi process areas).Greenhill: University of Glasgow.

[2]. Robertson \& Sribar. 2015, IT infrastructure strategies to manage change and enable growth. Greenhill: University of Glasgow.

[3]. Bahrul Ulum, (2014). Sistem permintaan jasa perbaikan komputer PT. Indo Tirta Abadi. Tangerang: Skripsi.

[4]. Dini Amelia Rahmah, (2013). Sistem Pemohonan bantuan Helpdesk Berbasis Website Pada Dinas Koperasi Daerah Jawa Tengah.Tangerang: Skripsi.

[5]. Nurhadianto, (2014). Sistem Permohonan jasa Infrastruktur pada PT.Saedong Cikande-Serang. Tangerang: Skripsi.

[6]. Lynda Applegate.2014, Corporate Information Strategy and Management. McGraw: Hill International Edition.

[7]. Chris Bates.2016, Web Programming: Building Internet Applications, 3ed. United States: Publisher. 